\title{
A Fundarte e o Ensino de Música: o impacto da instituição na educação musical de uma região
}

\section{Fundarte and Music Education: the institution's impact on music education in a region}

\author{
Cristina Rolim Wolffenbüttel ${ }^{1 *}$, Bárbara Cecília Spohr ${ }^{2}$
}

\begin{abstract}
RESUMO
A presente pesquisa objetivou investigar o impacto causado pela Fundação Municipal de Artes de Montenegro (Fundarte) no desenvolvimento da educação musical e cultural no Vale do Caí/RS. A instituição vem, há muitos anos, sendo referência no ensino de música na região e no estado. Em uma abordagem qualitativa, utilizou-se a pesquisa documental como método, sendo coletados documentos institucionais oficiais da Fundarte e reportagens em um jornal local, este, referência em comunicação da região, datadas de 2017 a 2020. O referencial teórico teve como base estudos de Kraemer (2000) e Swanwick (1999), considerando-se a educação musical e suas relações com diversos tempos, espaços e disciplinas. Como resultados, constatou-se que a Fundarte tem um papel importante na difusão e no desenvolvimento da arte e da cultura, oportunizando o ensino e a pesquisa na região do Vale do Caí/RS, bem como nas localidades do entorno. Como desdobramentos, almeja-se que esta pesquisa fomente outras investigações, não somente no que diz respeito à Fundarte, mas, também, de outras instituições da mesma natureza, que contribuem para a história e fortalecem ainda mais a área da educação musical.
\end{abstract}

Palavras-chave: Educação Musical; Fundarte; Interdisciplinaridade;

\section{ABSTRACT}

This research aimed to investigate the impact caused by the Municipal Foundation of Arts of Montenegro (Fundarte) in the development of musical and cultural education in Vale do Caí/RS. The institution has been, for many years, a reference in music education in the region and in the state. In a qualitative approach, documentary research was used as a method, collecting official institutional documents from Fundarte and reports in a local newspaper, this one, a reference in communication in the region, dated from 2017 to 2020. The theoretical framework was based on studies from Kraemer (2000) and Swanwick (1999), considering music education and its relationships with different times, spaces and disciplines. As a result, it was found that Fundarte has an important role in the dissemination and development of art and culture, providing opportunities for teaching and research in the region of Vale do Caí/RS, as well as in the surrounding areas. As a result, it is expected that this research will encourage further investigations, not only with regard to Fundarte, but also of other institutions of the same nature, which contribute to history and further strengthen the area of music education.

Keywords: Music education; Fundarte; Interdisciplinarity;

${ }^{1}$ PPGED-MP/UERGS. Universidade Estadual do Rio Grande do Sul. Unidade no Litoral Norte/RS. *E-mail: cristina-wolffenbuttel@uergs.edu.br

${ }^{2}$ Universidade Estadual do Rio Grande do Sul. Unidade em Montenegro. 


\section{INTRODUÇÃO}

A Fundação Municipal de Artes de Montenegro (Fundarte) vem, há meio século, desempenhando papel importante no que diz respeito às ações no campo cultural, artístico e educacional. Localizada na Região do Vale do Caí, estado do Rio Grande do Sul, é uma referência como pólo cultural do estado, tendo oportunizado o acesso às programações culturais, ao ensino e à pesquisa em arte, atingindo crianças, jovens, adultos e idosos.

A Fundarte teve seu início nos anos de 1959, à época como Conservatório Municipal de Música. Todavia, o funcionamento deu-se somente a partir de 1962, tendo a orientação e a administração sob a responsabilidade da Escola Normal São José, e a subvenção financeira da Prefeitura Municipal de Montenegro (OLIVEIRA, 1973). O foco era o ensino de música, sendo ofertados, na ocasião, os cursos de piano, violino, acordeão, sopros, canto, teoria musical e solfejo.

Em 1964, devido às dificuldades financeiras, a instituição teve suas portas fechadas. Retornou às atividades somente em 1973, porém, com a diminuição da oferta de cursos, sendo disponibilizados, apenas, piano e teoria musical (KAUTZMANN, 1979, 1982). No ano de 1984, a Fundarte transformou-se em Fundação Municipal de Artes de Montenegro. A manutenção financeira passou a ocorrer por meio de dotação orçamentária municipal, doação de empresas e pelo pagamento de mensalidades dos alunos.

Atualmente, a Fundarte é referência local, regional e nacional pela difusão e desenvolvimento da arte e da cultura, como escola de artes, ofertando o ensino das quatro áreas artísticas (artes visuais, dança, música e teatro), além de promover diversas ações sociais que descentralizam a arte, oportunizam o resgate da cultura e contribuem significativamente para a vida da comunidade e para o desenvolvimento da educação. A Fundarte tem reconhecimento nacional e internacional, devido à qualidade das atividades oferecidas, dos eventos artísticos e científicos promovidos, além dos cursos de artes e de aperfeiçoamento educacional (WOLFFENBÜTTEL, 1996).

Com base neste histórico, a presente pesquisa investigou o impacto causado pela Fundarte no desenvolvimento da educação musical e cultural no Vale do Caí/RS, a partir de reportagens publicadas em jornais locais, notadamente o Jornal Ibiá. Apresenta-se, desse modo, a trajetória dos últimos anos, desvelando o impacto causado pela instituição no ensino de música na região. 


\section{REVISÃO DE LITERATURA}

A revisão de literatura selecionada para esta pesquisa partiu da busca de periódicos científicos brasileiros, chegando ao resultado de 152 títulos selecionados, sendo 73 relacionados à cultura, 68 à arte e 11 à música.

Após a coleta dos periódicos, partiu-se para uma busca interna em cada uma das revistas, a fim de verificar os artigos pertinentes à pesquisa, e tendo como base os termos de busca: música, conservatório, instituição cultural e escola de arte. Por fim, após esta etapa, chegou-se ao número de oito artigos que se apresentaram pertinentes à investigação (FERREIRA FILHO, 2015; CLÍMACO, 2015; AUBIN, 2016; DAZZI, 2017; FAÇANHA; VIEIRA, 2017; SILVA, 2018; SANTOS; FERRONATO; MECENAS, 2019; FRESCA, 2020).

O artigo de Ferreira Filho (2015) é um recorte de sua dissertação, e tem como enfoque a trajetória de um dos departamentos da Academia Lorenzo Fernandez, bem como os métodos educativos e aspectos artísticos envolvidos. A pesquisa utilizada foi a documental, sendo os dados coletados em relatórios e matérias de jornal, além de referências bibliográficas. O Departamento, tendo como foco o ensino erudito de piano, estava localizado em Teresina (Piauí), iniciando as atividades em 1972, com o protagonismo da pianista Neusa de Almeida do Rego Monteiro. A instituição contribuiu de forma significativa para o cenário da educação musical teresinense, tendo a formação de diversos pianistas ao longo de seus 13 anos de funcionamento. Contribuição essa, em nível de profissionalização da área, tendo sido o ponto de partida da formação de musicistas e educadores musicais (FERREIRA FILHO, 2015).

Outra pesquisa importante e que contribuiu para a construção do objeto de pesquisa sobre a Fundarte foi empreendida por Clímaco (2016). O artigo (2016) apresenta um entrelaçamento entre o contexto social da cidade de Brasília (DF), em que o gênero musical choro deteve espaço significativo para a cultura local e nacional. O texto enfoca, também, os processos de ensino formal, não-formal e informal do choro na Escola Brasileira de Choro Raphael Rabello e as práticas e as vivências culturais, promovidas através do Clube do Choro. Em uma abordagem bibliográfica, a autora traz à tona autores que tratam de aspectos referentes às questões de gênero e aos processos de atualização/significação/ressignificação do choro. Além disso, trata das representações sociais, que nos processos simbólicos caracterizam manifestações culturais e intelectuais 
que constroem aspectos identitários de determinados grupos. Além de imbricar o contexto histórico-cultural do ambiente escolar e os processos de ensino e aprendizagem (CLÍMACO, 2016).

Focalizado em uma abordagem histórico-social da contribuição musical e política do intelectual e musicólogo Curt Lange, na capital mineira, na década de 1940, o artigo de Aubin (2016), publicado na Revista Opus, apresenta um recorte temporal, que contempla a criação e a trajetória do Conservatório Mineiro de Música, em 1925. Diferente da visão epistemológica da educação musical e do fomento à cultura e às práticas culturais, este artigo debruça-se sobre as questões políticas e a "rede de sociabilidade" que permeiam a continuidade e existência de instituições de ensino de música. Esta pesquisa documental resgatou, a partir de matérias publicadas em jornais e da análise de correspondências, a noção de espaço como conformadora da música erudita, estabelecendo uma rede de sociabilidade política.

Dazzi (2017) descreveu a trajetória da Academia Imperial de Belas Artes, a partir dos anos 1880 que, devido às transformações políticas do país, transformou-se em Escola Nacional de Belas Artes. De um ponto de vista histórico, o artigo traz as alterações pedagógicas do ensino de arte, baseadas no relatório redigido por Rodolpho Bernardelli, primeiro diretor da Escola Nacional de Belas Artes, em 1891. A pesquisa objetivou compreender a trajetória da instituição e, também, como as transformações decorridas da Reforma de 1890 e a nova organização governamental interferiram no desenvolvimento da instituição. O artigo não só contribuiu para a memória da instituição, mas, também, possibilitou o entendimento das transformações no contexto artístico-cultural e a representação da autoridade da escola como principal instituição de ensino do país, na época da Nova República.

No artigo de Façanha e Vieira (2017), a trajetória centenária do Instituto Estadual Carlos Gomes, localizado no estado do Pará, é apresentada. A importante instituição foi investigada com o objetivo de interpretar e analisar o conjunto de narrativas propostas na obra de Barros e Vieira (2015), na qual constam 58 relatos de professores que atuam ou atuaram no instituto. Fundamentada em uma perspectiva interdisciplinar, a pesquisa utilizou diferentes teóricos que tratam dos conceitos de memória, habitus e campo. Os resultados apresentados mostram a permanência das memórias e do campo da música na cultura local, bem como o desejo que o Instituto Estadual Carlos Gomes permaneça como referência no ensino de música no Pará. 
No recorte da pesquisa de mestrado em história social de Silva (2018) são demonstrados os limites e as potencialidades de pesquisar sobre o Conservatório de Música do Rio de Janeiro, considerando-se que as produções bibliográficas a esse respeito são escassas. $\mathrm{O}$ artigo afirma que a instituição contribuiu significativamente para o cenário musical da época, tanto na profissionalização e consolidação do mercado de trabalho quanto no desenvolvimento de sua própria metodologia de ensino da música. Com base na pesquisa documental, visto que os documentos coletados e analisados foram encontrados em arquivos e acervos do Rio de Janeiro, o artigo fundamentou-se no resgate da história da instituição, priorizando o conhecimento e a análise de sua trajetória.

Priorizando a formação em nível superior de professores de música, o artigo de Santos, Ferronato, Mecenas (2019) apresenta e analisa alguns aspectos da história dos conservatórios brasileiros de canto orfeônico. De caráter histórico, bibliográfico e oral, a pesquisa, ancorada nos conceitos como instituições educativas e currículo, buscou compreender as trajetórias diversificadas das escolas que, através da posição do estado, incluíram em suas diretrizes curriculares a disciplina de canto orfeônico. $\mathrm{O}$ artigo ressaltou a formação de professores nacionalistas, a supervalorização da cultura brasileira e a preparação pedagógica e didática do professorado para o ensino de música no contexto escolar.

O artigo de Fresca (2020), também publicado na Revista Opus, ressaltou as lutas e as questões administrativas presentes na fundação e permanência de conservatórios de música. A autora discutiu as influências da consolidação da escola franco-belga de violino no Conservatório de Bruxelas, sob as práticas pedagógico-musicais e de performance dos músicos brasileiros e, também, na fundação do Instituto Nacional de Música, no Rio de Janeiro, a partir de 1890. Em uma revisão bibliográfica, a autora ressaltou, ainda, que as concepções musicais adotadas pelas instituições estão intimamente ligadas ao âmbito político do período.

As pesquisas encontradas e apresentadas nesta revisão de literatura permitiram a construção e o aprofundamento do entendimento do objeto de estudo da presente pesquisa, a com vistas à investigação quanto ao impacto causado pela Fundarte no desenvolvimento da educação musical e cultural no Vale do Caí/RS. Desse modo, entende-se que Ferreira Filho (2015), Clímaco (2015), Aubin (2016), Dazzi (2017), Façanha e Vieira (2017), Silva (2018), Santos, Ferronato; e Mecenas (2019) e Fresca (2020) ajudaram neste processo. 


\section{REFERENCIAL TEÓRICO}

Esta investigação utilizou dois referenciais teóricos referentes ao campo da educação musical, sendo estes os propostos por Kraemer e Swanwick.

Kraemer (2000), trazendo um aparato epistemológico para uma análise fundamentada em elementos de práticas músico-pedagógicas e seus entrelaçamentos com diferentes áreas das ciências humanas, e Swanwick (1999), que sistematiza os valores da música e o significado metafórico expresso no contexto social de compreensão musical.

\section{A Epistemologia da Educação Musical, por Kramer}

A base teórica proposta por Rudolf-Dieter Kraemer (2000) discute o campo epistemológico da educação musical, abordando questões pertinentes ao tema. $\mathrm{O}$ autor preocupa-se com uma construção da teoria da educação musical, partindo do princípio de que a pedagogia da música está entrelaçada com outras disciplinas. O autor (KRAEMER, 2000) esclarece que a pedagogia da música se ocupa com as relações entre pessoa(s) e música(s); por isso, acaba dividindo seu objeto de estudo com as ciências humanas. Exemplifica essas disciplinas enfocando-as quanto aos aspectos filosóficos, históricos, psicológicos, sociológicos, musicológicos, pedagógicos e outras áreas que possam ter um significado pedagógico-musical específico.

Segundo Kraemer (2000, p. 58), pedagogia da música e a musicologia "unem-se no esforço comum em compreender a música”. Os aspectos musicológicos são apresentados, considerando-se a pesquisa musicológica - etnomusicologia, acústica, teoria da música, entre outras áreas - tratando de uma "possível análise e interpretação global dos eventos musicais", sendo os parâmetros musicais propriamente ditos. A didática da música interessar-se-ia pelos significados que as manifestações musicais poderiam adquirir no processo educacional. Os aspectos pedagógicos partem da pedagogia, que se ocupa "com teorias da educação e formação, premissas, condições, processos e consequências da ação educacional e didática, com questões sociais e institucionais, com problemas do ensino, da aprendizagem e didáticos" (KRAEMER, 2000, p. 59).

Kraemer (2000) discute o entrelaçamento da pedagogia da música com outras disciplinas. Ressalta-se que uma perspectiva de entrelaçamento da área considera-a como 
resultante do enlace recíproco entre as disciplinas, criando uma espécie de teia. Essa concepção de entrelaçamento propõe uma dimensão alargada da área, com limites mais abrangentes e flexíveis.

Para Kraemer (2000, p. 61), no “centro das reflexões musicais estão os problemas da apropriação e transmissão da música". Pedagogia e pedagogia da música não se constituem disciplinas isoladas e resultam diferentes agrupamentos da área. São disciplinas de integração orientadas na ação, conforme o objeto de pesquisa. $\mathrm{O}$ autor afirma que a particularidade do saber pedagógico-musical está "no cruzamento de ideias pedagógicas marcadas pelas ciências humanas, orientadas pela cultura musical e ideias estético-musicais". Além do conhecimento sobre os fatos e os contextos pedagógicomusicais, também é necessário colocar à disposição os princípios de explicação da prática músico-educacional, para as decisões, orientações, esclarecimentos, influências e melhorias dessas práticas,

Por fim, Kraemer (2000) propõe um modelo estrutural da pedagogia da música, o qual inclui a análise e os campos de aplicação da área, os aspectos que a compõem musicológicos, pedagógicos, entre outros - além das funções da pedagogia da música compreender e interpretar, descrever e esclarecer, conscientizar e transformar a prática músico-educacional.

\section{A Educação Musical, por Swanwick}

Em seu trabalho dedicado aos educadores musicais, Swanwick (1999) explorou os valores da música e o significado metafórico expresso no contexto social de compreensão musical. O autor postulou conceitos específicos da educação musical, através de experiências musicais, apresentando princípios fundamentais para professores de música em contextos diversificados através da exploração de algumas das implicações do ensino de música institucionalizado, tanto por escolas quanto por conservatórios privados.

Segundo Swanwick (1999) o conceito de estética é usualmente definido por uma grande variedade de maneiras, o que resulta numa confusão de determinações diferentes acerca do estético, do artístico e do afetivo. Supõe-se, a partir daí, que, ao considerar a visão de uma espécie particular de estética, a mesma englobaria todas as expressões e experiências artísticas em um grupo genérico. Existem três principais definições para este 
grupo: A primeira é que todas as formas de arte criam formas de vida expressivas; a segunda é o fato de todos seus significados dependerem de suas construções originais, não podendo ser extraídos sem uma considerável perda de significado. A terceira, de que necessitam de uma resposta estética, uma resposta por meio de sentimentos, sentidos e imaginação.

O principal problema em relacionar as artes com um ideal de estética é de que se acaba caindo na perspectiva de que o afetivo e o cognitivo estão divididos, dando impulso a pensamentos errôneos como o de que artistas não pensam, ou que pesquisadores não fazem nada. Ao longo da década de 1990, o conceito "estético tornou-se campo de batalha entre educadores musicais" (SWANWICK, 1999, p. 21), criando inúmeras concepções, umas válidas, porém outras não tão adequadas. No sentido das práticas musicais, “quando envolvidos com uma performance em particular, construímos um conjunto de expectativas na música ocidental talvez vinculadas à direção melódica ou harmônica ou com a repetição de padrões rítmicos métricos" (SWANWICK, 1999, p. 22), a forma como respondemos às músicas está ligada com previsões, com pressupostos do que esperamos acontecer, sendo tensões ou relaxamentos gerados pelo acontecimento real da obra.

Em função da fragilidade do conceito de a estética estar diretamente relacionada à separação que ela promove entre música e outras formas de artes, ou até mesmo outras formas de discursos considerados primordiais, devido ao fato de terem sido desenvolvidos antes da música, Swanwick (1999, p. 23) propõe a seguinte reflexão: “O que a música compartilha com as outras formas simbólicas?". Neste sentido, o autor explica:

A música não é uma anomalia curiosa, separada do resto da vida: não é só um estremecimento emocional que funciona como atalho para qualquer processo de pensamento, mas uma parte integral de nosso processo cognitivo. É um caminho de conhecimento, de pensamento, de sentimento. Naturalmente, em alguns aspectos a atividade musical é única. Ela realiza um trabalho especial, a fim de que palavras ou imagens visuais sejam menos satisfatórias ou, frequentemente, impossíveis. (SWANWICK, 1999, p. 23).

De acordo com o autor, o processo metafórico no sentido musical funciona em três níveis interdependentes. O primeiro deles é quando escutamos notas musicais como se fossem melodias. Quando ocorre de escutarmos tais melodias, assumindo-as como novas relações cosntitui-se como o segundo nível. Por fim, o nível três, para Swanwick (1999), ocorre quando as novas relações se unem com experiências prévias. 
A música é a mais abstrata de todas as artes; diferentemente de áreas como o teatro, que agem diretamente no campo da representatividade e dos signos, a música, no sentido de associação aos aspectos mundanos, encontra-se mais vinculada às sensações como o sentimento de peso psicológico em determinadas situações, quando estamos mais sentimentais ou sem tantas atribulações mentais, por exemplo. Estas experiências situacionais deixam resíduos no subconsciente, que podem ser ativados posteriormente, assombrando o sistema nervoso e/ou muscular, e, assim como estes sentimentos tomam formas diferentes, crescendo, diminuindo, mudando, eles encontram semelhanças com os movimentos musicais.

Segundo Swanwick (1999), ao avaliar seus alunos, considera que o professor de música necessite ter uma sensibilidade articulada, compreendendo que a complexidade da experiência musical não pode ser reduzida à dimensão técnica da execução. Existem aspectos mais profundos a serem observados, comumente confundidos com musicalidade natural ou talento/dom para a música. Tendo em vista estes aspectos, o autor sugere que se aproxime das ideias de música como metáfora, concentrando-se "nas camadas externas visíveis em ambos os lados de cada transformação metafórica" (SWANWICK, 1999, p. 85), para identificar produtos específicos da avaliação.

\section{METODOLOGIA}

Esta investigação teve por base a abordagem qualitativa (DENZIN; LINCOLN, 2006), a pesquisa documental como método (GIL, 2010), e a análise de conteúdo (MORAES, 1999) como técnica para a análise dos dados.

A abordagem qualitativa tem por característica situar o pesquisador no contexto do seu objeto de pesquisa. Conforme Denzin e Lincoln (2006, p. 17), esta se constitui "um conjunto de práticas materiais e interpretativas que dão visibilidade ao mundo. Essas práticas transformam o mundo em uma série de representações, incluindo as notas de campo, as entrevistas, as conversas, as fotografias, as gravações e os lembretes”.

Este tipo de investigação objetiva a coleta dos dados em seu ambiente natural, tendo por base a descritividade, a ênfase no processo ao invés do produto, a forma indutiva da análise dos dados, e a atenção especial destinada ao significado. A maneira como a presente investigação foi conduzida apontou um diálogo entre investigador e sujeito, para que não ocorresse de forma neutra; a abordagem qualitativa não pretendeu 
quantificar os dados obtidos, mas analisá-los em sua particularidade, considerando que o objetivo foi investigar o impacto causado pela Fundarte no desenvolvimento da educação musical e cultural da Região do Vale do Caí/RS.

A pesquisa documental caracteriza-se "pela busca de informações em documentos que não receberam nenhum tratamento científico, como relatórios, reportagens de jornais, revistas, cartas, filmes, gravações, fotografias, entre outras matérias de divulgação" (OLIVEIRA, 2007, p. 69). Utiliza os dados que ainda não foram tratados de modo científico ou analítico, que são as chamadas fontes primárias (GIL, 2010). Os documentos analisados podem ser atuais ou antigos, e utilizados para contextualização histórica, cultural, social e econômica de um lugar ou grupo de pessoas, em determinado momento da história.

Os dados para esta pesquisa foram coletados em reportagens de um jornal local de significativa circulação na região, o Jornal Ibiá, e no Programa do Curso de Música da Fundarte, com a vigência de 2019 a 2022. Informações complementares foram obtidas no site oficial da Fundarte. Todos os dados foram organizados de duas formas, originando o Caderno do Programa do Curso de Música da Fundarte (CPCMF) e o Caderno de Reportagens sobre Atividades da Fundarte (CRAF). O CPCMF somou 160 páginas, e o CRAF foi organizado em 80 páginas.

Após a coleta dos dados, foi realizada a análise de conteúdo, uma técnica utilizada para a descrição e interpretação de conteúdo, através da condução de "descrições sistemáticas, qualitativas e quantitativas" (MORAES, 1999, p. 9), que ajudam na interpretação de mensagens e significados presentes nos dados brutos. De acordo com o autor, existem cinco etapas a serem trilhadas, que são preparação das informações, unitarização ou transformação do conteúdo em unidades, categorização ou classificação das unidades em categorias, descrição e interpretação. Durante a preparação, o material coletado foi lido e identificado, sendo-lhe atribuídos códigos ou identificações. Quando do momento da unitarização, a unidade de análise foi isolada, reescrita e identificada. $\mathrm{Na}$ categorização ocorreu a redução dos dados coletados. Na descrição foram produzidos textos-síntese para cada categoria. Por fim, a interpretação foi o momento dedicado à união dos referenciais teóricos aos dados coletados, à construção de uma teoria acerca dos questionamentos de pesquisa e suas resoluções. Após a coleta e interpretação dos dados, resultaram cinco categorias temáticas, sendo elas: elementos das práticas 
educativas, eventos educacionais e de pesquisa em arte, apresentações musicais dos alunos, programações culturais e projetos multidisciplinares.

\section{RESULTADOS E ANÁLISE DOS DADOS}

Após a coleta dos dados, que permitiu a reunião de documentos dos anos de 2017 a 2021, foram encontradas 185 reportagens, juntamente com o Programa do Curso de Música da Fundarte, documento que apresenta aspectos específicos de cada curso ofertado pela instituição. Tais registros comprovam esta importância da Fundarte, em diferentes aspectos. Todo este material foi analisado e categorizado, resultando as categorias: elementos das práticas educativas, eventos educacionais e de pesquisa em arte, apresentações musicais dos alunos, programações culturais e projetos multidisciplinares, tratadas a seguir.

\section{Elementos das Práticas Educativas}

A categoria elementos das práticas educativas resultou da análise documental realizada no Programa do Curso de Música da Fundarte, de 2019 a 2022, documento no qual são apresentados os planejamentos metodológicos e as organizações disciplinares dos cursos oferecidos pela instituição. Foram coletadas, para a realização desta pesquisa, todas as partes referentes aos cursos de música, que são apresentados no documento de forma sucinta, apresentando a base teórica que fundamenta o trabalho de cada professor, juntamente com a relação dos conteúdos trabalhados em cada modalidade.

De acordo com os dados coletados, constata-se que são inúmeros os cursos oferecidos pela instituição, atingindo as faixas etárias dos três aos 94 anos de idade. O curso de música tem como objetivo principal o desenvolvimento dos elementos técnicos necessários para realização musical de diferentes gêneros musicais e repertórios dos instrumentos.

Em se tratando dos diferentes cursos de música, em seus aspectos metodológicos e curriculares, estes são planejados cuidadosamente pelos professores, conforme as necessidades dos alunos e dos conteúdos, considerando-se a diversidade de concepções de educação, e integrando-as, com vistas à obtenção dos resultados mais exitosos. 
A análise do plano de curso destacou muitos elementos importantes de cada um; porém, as metodologias variadas apresentaram algumas semelhanças, as quais foram associadas na pesquisa às concepções de educação que contemplavam diferentes elementos de desenvolvimento musical (SWANWICK, 1999). De acordo com o autor, o processo metafórico, no sentido musical, funciona em três níveis interdependentes. $\mathrm{O}$ primeiro, quando são escutadas notas musicais como se fossem melodias; depois, quando são escutadas as tais melodias, assumindo novas relações; e, por fim, quando as novas relações se unem às experiências prévias.

As aulas de música são providas do conhecimento teórico e humano, que caracterizam a prática de ensino de música contemporânea, usufruindo destas diferentes áreas metafóricas (SWANWICK, 1999). Este processo acompanha o desenvolvimento disciplinar dos alunos, possibilitando uma análise consubstanciada de sentidos, não somente musicológicos, mas, também, psicológicos e sociais, tão importantes no desenvolvimento musical.

Desta maneira, a instituição vem, há anos, contribuindo significativamente com o cenário da educação musical na região, através da oferta de seus cursos e de outras atividades. Exemplos da repercussão destas práticas encontram-se nas reportagens publicadas pelo Jornal Ibiá, a respeito das atividades desenvolvidas nos anos de 2017 a 2020.

\section{Eventos Educacionais e de Pesquisa em Arte}

Os eventos educacionais de pesquisa e arte dizem respeito às ações proporcionadas pela Fundarte, e que visam ao ensino do instrumento, ao aperfeiçoamento da prática musical, à performance, à pesquisa e ao desenvolvimento cultural. Nesta categoria estão inseridos os encontros de estudantes de instrumentos musicais, as edições do Seminário Nacional de Arte e Educação, os encontros de educação musical, workshops e oficinas. Nestes eventos podem ser encontrados discentes e docentes internos e externos

à Fundarte, proporcionando novas visões e experiências. Dentre as reportagens, os encontros de instrumentos musicais prevalecem em número. Encontram-se nesta categoria os Encontros de Orquestras, Encontros de Coros Infantis e Adultos, Encontros de Flauta e Piano, Encontros de Violinos e Encontro de Acordeão (CRAF, 2021). Ressaltam-se, neste sentido, os Encontros de Violinos, ocorridos desde maio de 2017. 
O primeiro evento, relacionado aos encontros de instrumentos musicais, segundo reportagem publicada no Jornal Ibiá, reuniu cerca de "70 alunos dos municípios de Montenegro, Brochier, Portão, Teutônia, Porto Alegre e Caxias do Sul, com idades entre 07 e 45 anos e diferentes níveis de conhecimento em violino". Com oficinas e atividades ligadas à prática instrumental, o evento teve como foco a metodologia Suzuki de ensino musical, a qual conta com o âmbito familiar do aluno inserido à prática discente em música. Ao longo das atividades do evento, os familiares participaram juntamente com os alunos e, ao final, houve uma apresentação no Teatro Therezinha Petry Cardona ${ }^{3}$, em que os alunos puderam mostrar ao público o que aprenderam durante o evento (CRAF, 2021).

Posteriormente, ocorreu o $2^{\circ}$ Encontro de Violinos da Fundarte. O evento aconteceu nos dias 13 e 14 de abril de 2018, tendo uma estrutura semelhante a do ano anterior. O objetivo do evento foi

[...] reunir e integrar estudantes de violino de Montenegro e cidades próximas para fazer música em grupo. As atividades buscam aprimorar tanto os elementos musicais quanto às habilidades técnicas específicas do instrumento.

[...] encontro reuniu 48 estudantes de violino de Montenegro e cidades como Brochier, Pareci Novo, São José do Sul, Porto Alegre, Alvorada, Caxias do Sul e um grupo de pais e familiares de 13 alunos de Brasília. (CRAF, 2021, p. 12-13).

Assim como a primeira edição, o evento teve o foco no método Suzuki. Ao final, foi realizada uma apresentação coletiva, a fim de compartilhar os ensinamentos vividos durante os dois dias do Encontro de Violinos.

No mesmo ano, 2018, ocorreu a 26 $6^{\mathrm{a}}$ edição do Seminário Nacional de Arte e Educação, evento que reúne professores e estudantes interessados na temática da pesquisa em arte e educação. Contou com apresentação de trabalhos, palestras, workshops e oficinas, envolvendo as quatro áreas das artes (artes visuais, dança, música e teatro). Observa-se que há uma grande aceitação pelo público que acorre a estas atividades, envolvendo professores e estudantes de todo o país, conforme a reportagem publicada no Jornal Ibiá (CRAF, 2021).

\footnotetext{
${ }^{3} \mathrm{O}$ teatro fica localizado no prédio da Fundarte, foi inaugurado em 26 de setembro de 2002. Seu nome é uma homenagem à Professora Therezinha Petry Cardona, primeira diretora da instituição.
} 


\section{Apresentações Musicais dos Alunos}

Esta categoria reúne as apresentações artísticas dos alunos da Fundarte, tendo como foco as diversas manifestações artísticas. Nos dados coletados, as reportagens sobre os espetáculos datam de 2017 a 2019, sendo realizados presencialmente, na sede da Fundarte, além de outros espaços públicos ou estabelecimentos da comunidade.

A partir do ano de 2020, devido à pandemia de COVID-19 ${ }^{4}$, as apresentações ocorreram de forma remota, tendo sua transmissão on-line, por meio da TV Cultura do Vale $^{5}$. A Fundarte, de acordo com reportagens coletadas, ao longo dos anos de 2017 a 2020 realizou atividades que contemplaram apresentações dos alunos do Curso Básico de Música. Essas atividades foram nomeadas como saraus, recitais, espetáculos e serenatas.

Segundo as reportagens coletadas do Jornal Ibiá, os saraus de Curso Básico de Música da Fundarte ocorreram regularmente, objetivando integrar a "comunidade e familiares com os alunos e professores da instituição, além de ser uma oportunidade de mostrar o trabalho desenvolvido em sala de aula" (CRAF, 2021, p. 28). Os eventos, em sua maioria, foram gratuitos, sendo pagos, apenas, aqueles que tinham como objetivo arrecadar fundos para as instituições parceiras da fundação. Em 2020, também devido à pandemia de COVID-19, a Fundarte realizou saraus no formato de lives, em parceria com a TV Cultura do Vale. Estes foram transmitidos gratuitamente, por meio das plataformas YouTube e Facebook (CRAF, 2021).

Os recitais, outras atividades realizadas pela Fundarte, tiveram a estrutura semelhante a dos saraus, em que os alunos tiveram a oportunidade de apresentarem aos pais e à comunidade o que aprenderam durante o semestre. Trataram-se de apresentações consecutivas de alunos dos mais variados instrumentos musicais lecionados na Fundarte durante uma semana inteira. O evento ocorreu no Teatro Therezinha Petry Cardona, sendo a entrada franca. Segundo reportagens do Jornal Ibiá, os instrumentos com os quais os

\footnotetext{
${ }^{4}$ A pandemia de COVID-19, também conhecida como pandemia de coronavírus, é uma pandemia ainda em curso de COVID-19 no ano de 2021. Doença respiratória causada pelo coronavírus da síndrome respiratória aguda grave 2 (SARS-CoV-2), teve origem zoonótica, e o primeiro caso conhecido da doença remonta dezembro de 2019 em Wuhan, na China. O primeiro caso de COVID-19 foi confirmado no Brasil em 26 de fevereiro de 2020.

5 A TV Cultura do Vale é uma emissora de televisão brasileira com sede em Montenegro/RS, estando localizada no prédio da Fundarte. Sua programação está focada no telejornalismo e programas educativoculturais.
} 
alunos apresentaram-se nos recitais foram violoncelo, violino, acordeão, contrabaixo, canto, sopros, piano, flauta, guitarra, teclado e violão (CRAF, 2021).

Outro evento apresentado pelos alunos do Curso Básico de Música da Fundarte foi o espetáculo de final de ano. Em 2018, intitulado "Compositores Gaúchos: o som do Sul, do tradicional ao urbano" (CRAF, 2021, p. 30), o espetáculo trouxe, em sua programação, composições gaúchas com base em diversos gêneros musicais. "A atividade estimulou os alunos no exercício da prática musical por meio da relação com o público, colocando em prática o conteúdo trabalhado durante o ano em formato de espetáculo de música" (CRAF, 2021, p. 30). Segundo a reportagem, o evento teve a classificação livre e a entrada gratuita.

Os alunos do Curso Básico de Música também realizaram as Serenatas de Natal, que ocorreram no final de ano, como normalmente acontece. Consistem em apresentações de pequenos grupos musicais de alunos da instituição em estabelecimentos do comércio local da cidade de Montenegro. Muitos destes estabelecimentos são patrocinadores da fundação; outros tantos compõem a comunidade que frequenta os eventos da Fundarte (CRAF, 2021).

Da música erudita à popular, um dos objetivos das apresentações tem sido, ao longo dos anos, compartilhar com a comunidade o que é trabalhado em sala de aula com os alunos. Do mesmo modo, também serve para integrar as famílias com a instituição e proporcionar aos alunos a oportunidade de se apresentarem em público.

No que diz respeito aos objetivos pedagógico-musicais, as apresentações, organizadas no cotidiano das aulas, de modo adequado e saudável, é um excelente modo de educação musical, possibilitando a relação entre as pessoas, a partir de práticas musicais integrativas (KRAEMER, 2000).

\section{Programações Culturais}

As programações culturais, outra categoria apresentada nos dados desta pesquisa, são eventos que a Fundarte realiza sozinha ou em parceria com outras instituições, visando à propagação e ao desenvolvimento da arte e da cultura em Montenegro e região.

Há muitos anos, no início de cada mês, a Fundarte tem divulgado, em suas redes sociais, panfletos e cartazes, a programação cultural. Durante o ano são inúmeras as apresentações de artistas convidados; dentre eles podem ser destacados o grupo Juntos, e 
o grupo musical A Bandinha, vindo de Manaus/AM, através do projeto Sonora Brasil ${ }^{6}$. Destacam-se, também, o Quinteto Persch que, no espetáculo Lieder Konzert, brindou a comunidade com uma apresentação de músicas alemãs; o grupo Tambo do Bando, com lançamento de seu álbum; o Show Alô, Alô Elis Regina, um tributo à Elis Regina, entre outros importantes eventos (CRAF, 2021). Grande parte destes espetáculos ocorreu de forma gratuita, no Teatro Therezinha Petry Cardona.

Em 2020, à semelhança das demais atividades, as programações presenciais tiveram de ser canceladas, devido à pandemia de COVID-19, levando a fundação a pensar em alternativas para levar, de uma forma segura à comunidade, momentos de apreciação artística. Foi, então, que a Fundarte lançou o evento chamado Música a Domicílio, que consistiu em uma apresentação do pianista Rodrigo Soltton, intitulado Show Itinerante Levando Música até Você. Com o auxílio de um caminhão, o músico passou por diversas ruas da cidade de Montenegro, levando música para a comunidade (CRAF, 2021).

Ao coletar e analisar os dados desta pesquisa é possível construir relações teóricas a partir de Kraemer (2000), por exemplo, no que diz respeito ao modo como as ações protagonizadas pela Fundarte contemplaram o entrelaçamento das ciências humanas e atribuíram significados ao processo pedagógico-musical. A relação entre os conteúdos próprios do campo da música, os processos de socialização - reflexos das práticas coletivas e de apresentações musicais para familiares e comunidade, à estética musical do repertório - tanto aqueles executados pelos alunos quanto por eles apreciados nas programações mensais da instituição, a relação entre instrumentos e corpos - propostas de postura e movimentações de performance, os "sentidos de ações humanas, contextos definidos socialmente e possibilidades subjetivas de formação" (KRAEMER, 2000, p. 55). O enlace epistemológico da música foi recíproco nas disciplinas das ciências humanas, criando uma teia, e, dela, uma dimensão ampla da área. Para o autor, a presença deste enlace não tira a especificidade de cada área/disciplina, mas, sim, fortalece-as e as ilumina.

\footnotetext{
${ }^{6}$ É um projeto temático direcionado para a identificação e o resgate da memória da música brasileira. Incentiva novas práticas e novos hábitos de apreciação de música de concerto e de tradição oral, promovendo apresentações de caráter essencialmente acústico, que valorizam a autenticidade sonora das obras e de seus intérpretes. É realizado em espaços do SESC e de parceiros, em cidades previamente aprovadas em Projeto Nacional. No Rio Grande do Sul, o Circuito é realizado em formato de Mostra.
} 


\section{Projetos Multidisciplinares}

A categoria projetos multidisciplinares relacionou-se aos projetos culturais desenvolvidos pela Fundarte. Dentre estes, foram encontrados Ação Comunitária Fundarte, Projeto Dançar: Dança para Todos e o Projeto Me Inclua Nessa. Em complemento aos dados coletados nas reportagens, fez-se necessária a investigação no site oficial da Fundarte. Optou-se, assim, pelo acesso aos dados na página da Internet, para a melhor compreensão do que foram e como ocorreram os projetos, visto que as reportagens não contemplaram a totalidade das informações.

O projeto Ação Comunitária Fundarte foi realizado a partir de oficinas e workshops de artes, atendendo a cerca de 200 pessoas, dentre crianças, jovens e adultos. Esteve vinculado às escolas públicas ou associações de bairros de Montenegro/RS. O projeto buscou a descentralização da arte com vistas à promoção da vida. As atividades do Coro Saber Viver também integraram este projeto. Constituiu-se num grupo composto por pessoas idosas, a partir de 60 anos, tendo por objetivo de proporcionar uma melhor qualidade de vida para os participantes. Também fizeram parte das ações do projeto o workshop Contação de Histórias para Professoras da Rede Pública e a Camerata de Violões. Destaca-se, no caso da Camerata de Violões, a oferta de quatro vagas para deficientes visuais e/ou alunos com transtornos de desenvolvimento (FUNDARTE, 2019).

Conforme reportagem do Jornal Ibiá, datada de 2019, o projeto Ação Comunitária Fundarte "tem como objetivo principal oferecer formação na área de artes às crianças, jovens e adultos em situação social, cultural e educacional menos favorecida" (CRAF, 2021. p 76), através de atividades cotidianas envolvendo a arte e a cultura. "Busca, ainda, a descentralização e inclusão da comunidade" (CRAF, 2021. p 76) nas atividades desenvolvidas.

Ainda, no Jornal Ibiá, constaram reportagens sobre a mostra realizada no Teatro Therezinha Petry Cardona, destinada à comunidade. Conforme o registro no jornal, no evento apresentar-se-íam "o Coro Saber Viver, Camerata de Violões, Oficina de Flauta Doce e Oficinas de Violões das escolas: Ana Beatriz Lemos, Manoel de Souza Moraes, Walter Belian e Dona Clara Camarão" (CRAF, 2021, p. 76).

O Projeto Dançar: Dança para Todos, desenvolvido pela Fundarte desde 1996, tem sido uma ação social complementar à escola, tendo atendido a 180 crianças e jovens, 
através do Curso Básico de Dança, dentro e fora da sede da instituição. Essa ação tem buscado proporcionar às crianças e jovens a oportunidade de crescimento pessoal, através da dança, para fins de melhoria em seu processo de socialização e desempenho escolar, e compreensão da importância da arte como área de conhecimento, além de envolvê-los em processos poéticos orientados por profissionais reconhecidos em dança, no estado e país (FUNDARTE, 2019; CRAF, 2021).

O Projeto Me Inclua Nessa foi criado em 2007 para atender crianças, jovens e adultos com necessidades especiais, visando dar oportunidade de desenvolvimento de suas habilidades artísticas nas áreas de artes visuais, dança, música e teatro. Os alunos têm sido integrados aos cursos, interagindo e participando de todas as atividades inerentes ao processo educativo. No final do ano, como culminância do trabalho, eles participaram de uma mostra pública (FUNDARTE, 2019; CRAF, 2021).

O projeto Guitar Band, outro que integra os projetos multidisciplinares da Fundarte, surgiu nos anos de 1994, com o objetivo de formar um conjunto de instrumentistas de música popular, principalmente do Rock. Como o próprio nome sugere, o enfoque é a guitarra e as demais formações de bandas de música popular. À semelhança de outras ações da Fundarte, este projeto buscou destacar grandes guitarristas da história deste instrumento (FUNDARTE, 2019).

Como atividade que integrara as diversas ações da Fundarte, no ano de 2018 foi realizada uma apresentação da Guitar Band, em comemoração aos 45 anos da instituição (CRAF, 2021). Na ocasião, além da comunidade montenegrina, diversas escolas foram convidadas para o evento, buscando um entrelaçamento entre a performance e o ensino do instrumento musical, à comunidade escolar.

No ano de 2020, a instituição desenvolveu um projeto chamado Oficina de Musicalização Infantil. À semelhança das demais atividades naquele ano, e, também em anos subsequentes, devido à pandemia de COVID-19, o projeto ocorreu de forma virtual, aos sábados pela manhã, com duração de 50 minutos cada encontro. $\mathrm{O}$ curso foi dividido em dois grupos, sendo que o primeiro foi destinado às crianças de dois a três anos de idade, e o segundo, às crianças de quatro a cinco anos de idade. As atividades iniciaram em 7 de março e finalizaram em 12 de dezembro de 2020 (CRAF, 2021).

Ao coletar e analisar os dados desta pesquisa, que objetivou investigar o impacto causado pela Fundarte no desenvolvimento da educação musical e cultural no Vale do Caí/RS, observou-se que as inúmeras atividades que a instituição promoveu e continua a 
promover, possibilitaram vislumbrar o imbricamento de disciplinas proposto por Kraemer (2000). São ações que unem diversas áreas do conhecimento, fazendo com que a comunidade próxima, bem como a mais distante, consiga apreciar arte e música, resultando a compreensão, a partir da prática, das dimensões e funções do pensamento musical.

Do mesmo modo, em cada atividade aqui descrita, percebeu-se que a pedagogia da música e a musicologia, em suas diversas manifestações, estavam unidas no esforço para compreender a música (KRAEMER, 2000), oportunizando variadas e ricas apreciações musicais. Assim, as relações entre as pessoas e as músicas, em seus inúmeros desdobramentos, foram amplamente contatadas nesta investigação.

\section{CONSIDERAÇÕES FINAIS}

A Fundarte tem um papel muito importante na difusão e no desenvolvimento artístico e cultural, oportunizando o acesso a diferentes manifestações culturais, ao ensino e à pesquisa nas quatro áreas das artes na região, bem como em localidades próximas.

Constatou-se, a partir da coleta e análise dos dados desta pesquisa, o grande impacto resultante das ações da Fundarte, no que diz respeito ao desenvolvimento da educação musical e cultural que a instituião tem promovido na Região do Vale do Caí/RS. Como escola de artes e música, a Fundarte tem oportunizado inúmeros e valiosos aprendizados, tanto para montenegrinos quanto para moradores da região, de diferentes idades. Os cursos de música e os eventos artístico-culturais, tanto em anos que antecederam a pandemia de COVID-19 quanto em pleno momento pandêmico, têm sido uma maneira de as artes se apresentarem, contribuindo para o desenvolvimento do senso estético, como foi possível constatar nas reportagens do Jornal Ibiá, por exemplo.

Com base na leitura histórico-cultural e nos embasamentos epistemológicos da educação musical, observou-se que a instituição tem causado um impacto positivo e marcante no desenvolvimento da educação musical e cultural no Vale do Caí/RS. Ao longo dos anos, muitos dos alunos que tiveram sua trajetória musical inicial na Fundarte, hoje compõem o cenário musical do estado, além de atuarem na área da educação musical e, principalmente, integrarem o corpo docente da instituição.

Através de suas inúmeras ações, a Fundarte tem proporcionado um ensino de música de alta qualidade, caminhando entre diferentes concepções educacionais, 
intercambiando entre as demais disciplinas das ciências humanas, como musicologia, filosofia, história, sociologia, pedagogia, dentre outras, o que ultrapassa os limites teóricos e as linhas fronteiriças das disciplinas, compondo uma dimensão ampla, complexa e prática da aprendizagem e da educação como um todo.

Ao finalizar esta pesquisa e, com base nos dados coletados e na sua respectiva análise, espera-se que esta pesquisa, como desdobramentos, possa fomentar a criação e a preservação de outras investigações da mesma natureza, que contribuam para a história da educação musical e fortaleçam, ainda mais, a Região do Vale do Caí, do Rio Grande do Sul e, até, do Brasil.

\section{REFERÊNCIAS}

AUBIN, Myrian Ribeiro. Francisco Curt Lange e sua atuação nos meios musical e político em Belo Horizonte: constituição de uma rede de sociabilidades. Opus, [s.l.], v. 22, n. 1, p. 299-338, jun. 2016. Disponível em:

<https://www.anppom.com.br/revista/index.php/opus/article/view/354>. Acesso em 20 nov. 2021.

CLÍMACO, Magda de Miranda. Escola brasileira de choro Raphael Rabello e clube do choro: interação eficaz nos processos de significação e ensino do choro em Brasília.

Revista Música Hodie, Goiânia, V.15 - n.2, 2015, p. 137-150. Disponível em:

<https://www.revistas.ufg.br/musica/article/view/39759>. Acesso em 20 nov. 2021.

DAZZI, Camila Carneiro. Memórias da Academia: O Ensino da Arte no Início da República. Revista ENSINARMODE, v. 1, n. 1, p. 009-026, out 2017/jan 2018. Disponível em:

<https://www.revistas.udesc.br/index.php/ensinarmode/article/view/10408>. Acesso em 20 nov. 2021.

DENZIN, Norman K.; LINCOLN, Yvonna. A disciplina e a pratica da pesquisa qualitativa. In: DENZIN, Norman K.; LINCOLN, Yvonna (orgs). Planejamento da pesquisa qualitativa: teorias e abordagens. 2 ed. Porto Alegre: ARTMED, 2006.

FAÇANHA, Tainá Maria Magalhães; VIEIRA, Lia Braga. Memórias de um estabelecimento de ensino musical. Revista da ABEM, v. 25, n. 38, p. 105-122, jan/jun 2017. Disponível em:

<http://www.abemeducacaomusical.com.br/revistas/revistaabem/index.php/revistaabem /article/view/665>. Acesso em 20 nov. 2021.

FERREIRA FILHO, João Valter. Práticas e usos musicais no Piauí: apontamentos históricos. XXV Congresso da Anppom - Vitória/ES, Brasil, jun. 2015. Disponível em:

<https://www.anppom.com.br/congressos/index.php/25anppom/Vitoria2015/paper/view /3558/1091>. Acesso em 20 nov. 2021. 
FRESCA, Camila. Música e nacionalismo: lutas e disputas na fundação dos conservatórios do Rio de Janeiro e de Bruxelas. Opus, v. 26 n. 2, p. 1-19, maio/ago. 2020. Disponível em:

<https://www.anppom.com.br/revista/index.php/opus/article/view/opus2020b2602>. Acesso em 20 nov. 2021.

KRAEMER, Rudolf Dieter. Dimensões de funções do conhecimento pedagógicomusical. Em Pauta, Porto Alegre, v. 11, n. 16/17, abr./nov., p. 50-73, 2000. Disponível em: <https://seer.ufrgs.br/EmPauta/article/view/9378>. Acesso em 20 nov. 2021.

SANTOS, Elias Souza dos; FERRONATO, Cristiano de Jesus; MECENAS, Ane Luise Silva. Histórias dos conservatórios de canto orfeônico: consonâncias e dissonâncias nos cursos de formação do professorado de música. Revista Brasileira de História da Educação, v. 19, e081, 2019. Disponível em:

<https://www.scielo.br/j/rbhe/a/rcb7mt9GL88vnxxVvX8vPkj/abstract/?lang=pt>. Acesso em 20 nov. 2021.

SWANWICK, Keith. Teaching music musically. Abingdon: Routledge, 1999.

SILVA, Janaina Girotto da. Conservatório de Música do Rio de Janeiro: mapeamento documental e desafios para pesquisa. Revista Brasileira de Música, v. 31, n. 1, p. Jan./Jun. 2018. Disponível em:

<https://revistas.ufrj.br/index.php/rbm/article/view/26040/14025>. Acesso em 20 nov. 2021.

SOUZA, Sauloéber Tarsio de; COELHO, Nicula Maria Gianoglou. Educação Musical no Interior de Minas Gerais: a experiência da escola de acordeon de Ituiutaba (19561964). Revista: História e Cultura, Franca, v. 4, n. 3, p. 369-387, dez. 2015. 